\title{
PENGARUH LATIHAN DRIBBLE 20 YARDS SQUARE TERHADAP KEMAMPUAN MENGGIRING BOLA
}

\author{
Medrika Anggi R, Marta Dinata, Ade Jubaedi \\ Fakultas Keguruan dan Ilmu Pendidikan \\ Universitas Lampung \\ Email: medrikaanggiretama@gmail.com
}

\begin{abstract}
The problem in this study is that the ability to dribble students is not optimal. This study aims to determine the difference in influence by giving a treatment that is the exercise of 20 yards square dribble. The type of research used is an experiment with a sample of 30 people. Data collection techniques using dribbling instruments. Data analysis uses influence test data analysis techniques. The results showed that the training of dribble 20 yards square had a significant effect with t-count 8.48>t-table 2.045. The results of this study indicate that the training of dribble 20 yards square has a significant influence on the ability of herding on football extracurricular students of Pagar Dewa 1 State High School, Tulang Bawang Barat Regency.
\end{abstract}

Keywords: dribble 20 yards square, dribble

\begin{abstract}
ABSTRAK
Masalah dalam penelitian ini adalah kemampuan menggiring bola siswa belum maksimal. Penelitian ini bertujuan untuk mengetahui perbedaan pengaruh dengan memberikan suatu perlakuan yaitu latihan dribble 20 yards square. Jenis penelitian yang digunakan adalah eksperimen dengan sampel sebanyak 30 orang. Teknik pengumpulan data menggunakan instrumen menggiring bola. Analisis data menggunakan teknik analisis data uji pengaruh. Hasil penelitian menunjukkan bahwa latihan dribble 20 yards square memberikan pengaruh yang signifikan dengan nilai t-hitung 8,48 > t-tabel 2,045. Hasil penelitian ini menunjukkan bahwa latihan dribble 20 yards square memberikan pengaruh yang signifikan terhadap kemampuan menggiring pada siswa ekstrakurikuler sepak bola SMA Negeri 1 Pagar Dewa Kabupaten Tulang Bawang Barat.
\end{abstract}

Kata kunci: dribble 20 yards square, menggiring bola

\section{PENDAHULUAN}

Sepak bola merupakan salah satu cabang olahraga permainan yang banyak digemari masyarakat di Indonesia baik pria maupun wanita (Abid, dkk., 2013). Sepak bola tidak sekedar dilakukan untuk tujuan rekreasi dan pengisi waktu luang akan tetapi dituntut pula suatu prestasi yang optimal.

Menurut Sucipto, (2000: 7) "Sepak bola adalah permainan beregu, masingmasing regu terdiri dari sebelas pemain, 
dan salah satunya penjaga gawang." Meskipun termasuk dalam olahraga beregu, setiap pemain harus menguasai teknik dasar yang terdiri dari gerakan dengan bola maupun gerakan tanpa bola. Dalam permainan sesungguhnya, sepak bola dimainkan oleh dua kesebelasan. Masingmasing regu terdiri atas 11 pemain termasuk penjaga gawang, dan pemain cadangan untuk setiap regunya adalah 7 pemain. Adapun lama permainan ditentukan dengan babak, yakni 2 babak, satu babak lamanya 45 menit, dengan lama istirahat antar babak 15 menit.

Menurut Kurnia (2006: 7) "Sepak bola adalah salah satu jenis olahraga permainan yang dimainkan oleh 2 regu. Setiap regu terdiri atas 11 pemain, seorang diantaranya bertugas sebagai penjaga gawang." Sepak bola merupakan permainan beregu sehingga kerjasama tim sangat diperlukan walaupun kemampuan individu setiap pemain juga dibutuhkan. Tujuan dari permainan sepak bola adalah memasukkan bola ke gawang lawan sebanyak- banyaknya dan mencegah pemain lawan untuk membuat gol ke gawang bertahan sesuai dengan peraturan yang berlaku dalam permainan sepak bola. Selain itu, melalui permainan sepak bola diharapkan dapat menumbuhkan kerjasama dan interaksi sosial di dalam diri pemain. Lebih lanjut menurut Sucipto, (2000: 8), tujuan yang paling utama dan yang paling diharapkan untuk dunia pendidikan terutama pendidikan jasmani adalah sepak bola merupakan salah satu mediator untuk mendidik anak agar kelak menjadi anak yang cerdas, terampil, jujur, dan sportif.

Menggiring bola merupakan teknik dasar dengan bola yang sering digunakan dalam permainan sepak bola. Harsono (1988: 204), menjelaskan bahwa: "Komponen fisik yang diperlukan dalam cabang olahraga sepak bola antara lain; kekuatan otot, daya tahan otot, fleksibilitas, kelincahan, koordinasi dan power". Menurut Sucipto, (2000: 28), "pada dasarnya menggiring bola adalah menendang terputusputus atau pelan-pelan, oleh karena itu 
bagian kaki yang dipergunakan dalam menggiring bola sama dengan bagian kaki yang dipergunakan untuk menendang bola". Semua bentuk menggiring bola yang efektif didasarkan pada kombinasi keempat kemampuan adalah: (1) kemampuan mengontrol bola/penguasaan bola, (2) kemampuan melakukan gerak tipu, (3) kemampuan mengubah arah, dan (4) kemampuan mengubah kecepatan.

Menurut Soedjono, (1980: 61). Menggiring bola merupakan teknik dasar yang cukup memiliki peranan penting dalam sepak bola, tidak heran jika para pengamat sepak bola khususnya mengatakan bahwa mahirnya seorang pemain dapat dilihat dari bagaimana seorang pemain tersebut menggiring bola. Berdasarkan beberapa pengertian di atas, menggiring bola adalah kemampuan seseorang dalam menggerakan bola secara efektif dengan menggunakan kaki bagian tertentu. Saat menggiring bola bisa menggunakan kaki bagian dalam, kaki bagian luar atau pung- gung kaki tergantung situasi dan kondisi saat bermain.

Menurut Luxbacher, Joseph A (1997) latihan dribble 20 yards square merupakan salah satu bentuk latihan untuk membantu meningkatkan kemampuan dribble. Pada dribble 20 yards square, latihan ini menggunakan lapangan yang dibatasi oleh 4 cone sebagai penanda pembatas area dengan jarak masing-masing cone sekitar 5 yards yang berbentuk persegi. Pelaksanaan latihan dribble 20 yards square menggunakan aba-aba "mulai" pemain dribble bola ke cone pertama lalu membelok ke arah kanan ke cone ke 2 dan seterusnya sampai 4 cone terlewati.

Keuntungan dari metode latihan 20 yards square diantaranya dapat meningkatkan kecepatan dribble dan dapat meningkatkan kelincahan pada pemain, sedangkan kelemahan latihan dribble 20 yards square bola belum dapat dikuasai dengan baik, tenaga tidak efisien, dan teknik tidak selalu bagus dan sempurna, faktor kesulitan dalam melakukan latihan 
ini banyak pemain yang mengalami kejenuhan.

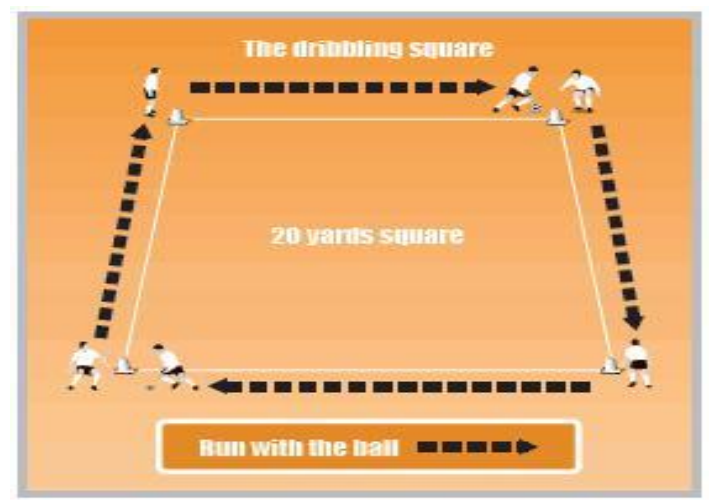

Gambar 1. Latihan Dribble 20 Yards Square

Berkaitan dengan sepak bola prestasi maka akan banyak hal yang harus dibicarakan dan dibahas. Sepak bola juga merupakan salah satu olahraga permainan yang sudah dimainkan sejak lama di berbagai negara, meskipun menggunakan kata istilah yang berbeda. Semua permainan itu memiliki tujuan yang sama, yaitu permainan yang dimainkan oleh dua tim dan pemain dari tiap tim berusaha memainkan bola dan menjaga bola agar tidak direbut oleh tim lawan dan berusaha memasukkan bola ke gawang lawan. (Febrianto, dkk., 2017).

Menurut Soedjono, (1980: 17) teknik dasar dalam sepak bola meliputi: menendang (kicking), menghentikan (stop- ping), menggiring (dribbling), menyundul (heading), merampas (tackling), lemparan ke dalam (throw-in), menjaga gawang (keeping). Sedangkan pengertian teknik dasar itu sendiri adalah semua kegiatan yang mendasari sehingga dengan modal sedemikian itu sudah dapat bermain sepak bola. Melatih tim sepak bola harus dimulai dengan mengajari setiap pemain berbagai teknik atau keterampilan dasar yang diperlukan untuk menghadapi kondisi yang muncul di dalam laga yang sesungguhnya. Sejak usia dini para pemain harus menguasai teknik permainan sepak bola. Setiap teknik yang diajarkan dikuti oleh program latihan yang konsisten dan berkelanjutan agar teknik tersebut dapat dikuasai dan menjadi keterampilan.

Teknik dalam permainan sepak bola meliputi dua macam teknik yaitu: teknik dengan bola dan tanpa bola. Teknik dasar bermain sepak bola yang harus dikuasai meliputi menendang bola, menghentikan bola, mengontrol bola, gerak tipu, tackling, lemparan ke dalam dan teknik 
menjaga gawang. Mengontrol bola di antaranya adalah menjaga dan melindungi bola dengan kaki untuk terus dibawa ke depan disebut juga menggiring (dribbling). Menggiring bola harus memiliki konsep dasar yang dikuasai agar dapat menggiring bola dengan baik. Pengertian Dribbling menurut Mielke (2007: 1) "adalah keterampilan dasar dalam sepak bola karena pemain harus mampu menguasai bola saat sedang bergerak, berdiri atau bersiap, melakukan operan atau tembakan." Dribble pada permainan sepak bola juga merupakan salah satu strategi yang biasa diterapkan. Kemampuan dribble pada seorang pemain sepak bola memiliki tujuan untuk melewati lawan, mencari kesempatan memberikan bola umpan kepada teman dengan tepat, serta menahan bola tetap dalam penguasaan sesuai dengan kegunaannya. Salah satu faktor kondisi fisik yang mendukung kemampuan seseorang dalam melakukan dribble adalah kelincahan dan kecepatan.
Menurut Harsono (1998: 172) kelincahan adalah kemampuan merubah arah dan posisi tubuh dengan tepat pada waktu sedang bergerak, tanpa kehilangan keseimbangan dan kesadaran akan posisi tubuhnya. Menurut Koger (2007: 51), konsep dasar yang harus di kuasai meliputi: (1) Ketika menggiring bola, usahakan bola agar terus berada di dekat kaki Anda, (2) Giringlah bola dengan kepala tetap tegak, (3) Jika anda bergerak ke arah musuh, perhatikanlah pinggang dan arah kaki mereka, (4) Gunakan beberapa gerak tipu untuk mengecoh lawan, (5) Variasikan kecepatan lari Anda, dengan mengubah-ubah kecepatan dan berbelok secara mendadak, (6) Giringlah bola menjauhi musuh Anda, (7) Carilah teman satu tim yang bebas dari kepungan lawan agar Anda dapat mengoper bola kepadanya. Menggiring bola tidak hanya membawa bola menyusuri tanah dan lurus ke depan melainkan menghadapi lawan yang jaraknya cukup dekat dan rapat. Hal ini menuntut seorang pemain harus memiliki kemampuan menggiring 
bola dengan baik. Dribbling berguna untuk

melewati lawan, mencari kesempatan memberi umpan kepada kawan dan untuk menahan bola tetap ada dalam penguasaan. Dribbling memerlukan ketrampilan yang baik dan dukungan dari unsur-unsur kondisi fisik yang baik pula seperti keseimbangan dan kelincahan dapat memberikan kemampuan gerak lebih cepat.

Berdasarkan observasi kegiatan ekstrakurikuler di SMA Negeri 1 Pagar Dewa Kabupaten Tulang Bawang Barat, siswa-siswa yang mengikuti ekstrakurikuler sepak bola memiliki kemampuan yang berbeda-beda dalam menggiring bola. Banyak siswa yang masih menggiring bola dengan menggunakan ujung kaki dan jarak kaki dengan bola terlalu jauh, sehingga mudah direbut lawan. Siswa lemah dalam penguasaaan bola sehingga bola mudah direbut lawan. Dalam menggiring bola siswa masih terlihat kaku. Ada sebagian siswa yang memiliki kecepatan dalam berlari, tetapi saat menggiring bola dalam kecepatan yang tinggi, siswa ter- sebut sulit untuk berbelok dan bola yang terlalu jauh dengan kaki. Saat menguasai bola sebagian siswa cenderung menguasai bola tersebut lalu melakukan dribbling tanpa memeperhatikan area sekitarnya. Siswa ekstrakurikuler sepak bola SMA Negeri 1 Pagar Dewa Kabupaten Tulang Bawang Barat saat berlari siswa mempunyai kecepatan yang tinggi tetapi tidak dapat membelokan tubuhnya secara cepat dan tepat. Sehingga tidak dapat melewati lawan dan bola mudah direbut.

Berdasarkan uraian di atas maka peneliti melakukan penelitian yang berjudul: "pengaruh latihan dribble 20 yards square terhadap kemampuan minggiring bola pada siswa ekstrakurikuler sepak bola SMA Negeri 1 Pagar Dewa Tulang Bawang Barat".

\section{METODE}

Di dalam penelitian ini peneliti menggunakan metode eksperimen. Desain yang digunakan dalam penelitian ini adalah One Group Pretest-posttest Design, 
Populasi dalam penelitian ini adalah seluruh siswa SMA Negeri 1 Pagar Dewa yang mengikuti ekstrakurikuler sepak bola berjumlah 30 orang.

Dalam penelitian ini tes yang digunakan adalah tes kemampuan menggiring bola (dribbling) menurut Nurhasan (2007: 212). Instrument dalam penelitian ini sudah baku dan dibukukan dalam bukunya Nurhasan (2007: 212) sehingga instrumen tersebut sudah dikatakan valid dan reliabel karena sudah teruji kevalidan dan kereliabelannya, sehingga tidak perlu dilakukan uji coba instrument lagi.

Tabel 1. Skala Penilaian Menggiring Bola

\begin{tabular}{|c|c|c|l|}
\hline No & Interval & Nilai & \multicolumn{1}{|c|}{ Keterangan } \\
\hline 1 & $22,01-23,04$ & 9 & Sangat Baik \\
\hline 2 & $23,05-25,07$ & 8 & Baik \\
\hline 3 & $25,08-27,10$ & 7 & Cukup Baik \\
\hline 4 & $27,11-29,13$ & 6 & Cukup \\
\hline 5 & $31,14-33,16$ & 5 & Kurang Baik \\
\hline
\end{tabular}

Teknik pengambilan data dilaksanakan dengan tes dan pengukuran. Dengan melalui tes dan pengukuran kita akan memperoleh data yang objektif. Tes adalah alat ukur yang dapat digunakan untuk memperoleh data yang objektif, sedangkan pengukuran adalah proses pengumpulan data atau informasi dari suatu objek tertentu dan dalam proses pengukuran diperlukan suatu alat ukur atau instrumen tertentu. Tes yang akan dilakukan oleh peneliti untuk penelitian ini akan dipaparkan sebagai berikut:

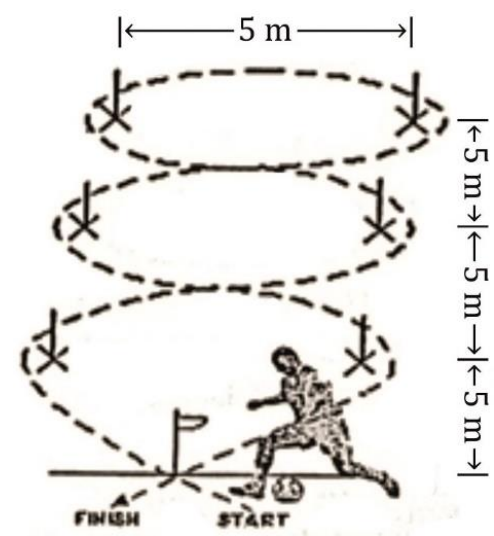

Gambar 2. Gambar Instrumen keterampilan dribbling

(Sumber: Nurhasan, 2007: 212)

1. Tes Keterampilan Dribbiling untuk mengukur kemampuan dribbling bola disertai perubahan arah;

2. Alat dan bahan: Lapangan sepak bola, cones, stopwatch, bola, meteran panjang, blangko dan alat tulis.

3. Pelaksanaan: 
a. Pada aba-aba "siap" testee berdiri di belakang garis start dengan bola pada penguasaan kakinya;

b. Pada aba-aba "ya" testee mulai menggiring bola dengan melewati setiap tiang bendera atau cones secara berurutan sampai ia melewati garis finish;

c. Apabila ada kesalahan (ada tiang bendera atau cones yang belum dilewati atau bahkan bola lepas dari kontrol kaki) maka harus diulangi tanpa menggunakan anggota badan selain kaki di mana kesalahan terjadi dan selama itu pula stopwatch tetap berjalan, sehingga testee menggiring bola dengan melewati tiang atau cones secara berurutan dan dilakukan pulang pergi;

d. Bola digiring dengan kaki kanan dan kiri secara bergantian, atau paling tidak salah satu kaki pernah menyentuh bola satu kali sentuhan; e. Testee dinyatakan gagal dan harus mengulang jika menggiring bola hanya menggunakan satu kaki saja, menggiring bola tidak melewati bendera atau cones secara berurutan dan menggunakan anggota badan lainnya selain kaki untuk menggiring bola;

f. Penilaian yaitu diberi nilai tes adalah waktu yang dicapai yang terbaik dari dua kali kesempatan yang diperoleh yang diukur dalam satuan detik.

Pelaksanaan pengumpulan data dalam penelitian merupakan faktor penting karena berhubungan langsung dengan data yang akan digunakan dalam penelitian, maka dalam pengumpulan data peneliti melakukan langkah-langkah dalam penelitian ini adalah sebagai berikut:

1. Tes Awal (Pre-Test)

Tes awal atau pre-test yaitu tes yang dilakukan pertama kali oleh peneliti dengan tujuan untuk menyamakan beban latihan dari masing-masing 
subyek, sehingga dapat diketahui perbedaan hasil yang dicapai setelah diberikan treatment atau perlakuan dalam 16 kali pertemuan. Sebelum melakukan tes awal peserta diberikan waktu untuk pemanasan.

2. Pemberian Perlakuan

Pemberian perlakuan (treatment) pada eksperimen ini dilaksanakan 16 kali pertemuan, dikarenakan itu dianggap sudah cukup memberikan perubahan, sehingga peneliti mencoba mengambil tes akhir setelah latihan yang dilaksanakan selama 16 kali pertemuan sesuai dengan batas waktu minimal latihan menurut (Bompa, 1994). Latihan ini dimulai pukul 15.00 WIB sampai selesai, latihan dilakukan 3 kali dalam seminggu yaitu pada hari Senin, Rabu, dan Jumat.

a. Pemanasan (Warming Up)

Latihan pemanasan (Warming $U p$ ) diberikan kepada pemain selama 15 menit, latihan ini sangat penting karena latihan ini dilaku- kan untuk menaikkan suhu tubuh dan menghindari risiko terjadinya cedera otot dan sendi-sendi pada peserta. Latihan yang merupakan kegiatan pemanasan dalam penelitian ini meliputi: stretching, Senam untuk kelentukan, pelemasan, penguatan yang meliputi otot leher, dada, lengan, pinggang, dan pemanasan yang dilakukan lebih dikhususkan pada cabang olahraga yang akan dipelajari yaitu sepak bola.

b. Latihan Inti

Latihan inti dilakukan oleh peserta yaitu latihan dribble 20 yards square.

3. Tes Akhir (Post Test)

Tes akhir yang digunakan dalam penelitian ini sama dengan yang dilakukan pada tes awal dengan tujuan untuk mengetahui hasil yang dicapai oleh tiap-tiap peserta tes setelah melaksanakan latihan. Hasil tes akhir dicatat untuk mengetahui pengaruh dari latihan tersebut. 
Tabel 2. Hasil Uji Normalitas

\begin{tabular}{|l|l|l|l|}
\hline \multicolumn{1}{|c|}{ Data } & Fhitung & Ftabel & Kesimpulan \\
\hline $\begin{array}{l}\text { Data Tes Awal Kelompok } \\
\text { Eksperimen Dribble 20 yards square }\end{array}$ & 0,151 & 0,381 & Normal \\
\hline $\begin{array}{l}\text { Data Tes Akhir Kel ompok } \\
\text { Eksperimen Dribble 20 yards square }\end{array}$ & 0,151 & 0,381 & Normal \\
\hline
\end{tabular}

Tabel 3. Hasil Uji Homogenitas

\begin{tabular}{|c|c|c|l|}
\hline \multicolumn{1}{|c|}{ Data } & F $_{\text {hitung }}$ & F $_{\text {tabel }}$ & Kesimpulan \\
\hline $\begin{array}{l}\text { Kelompok Eksperimen } \\
\text { Dribble 20 yards square }\end{array}$ & 1,37 & 3,33 & Homogen \\
\hline
\end{tabular}

Uji Normalitas data yang digunakan pada penelitian ini menggunakan uji liliefors dengan kriteria uji jika nilai Lhitung $<\mathrm{L}_{\text {tabel}}$, maka data tersebut berdistribusi normal. Berdasarkan hasil tes menggiring bola pada kelompok eksperimen dengan taraf signifikan 0,05 dan taraf kepercayaan 95\% memiliki nilai $\mathrm{L}_{\text {hitung }}$ yang lebih kecil daripada $\mathrm{L}_{\text {tabel, }}$ sehingga dapat disimpulkan bahwa distribusi data untuk semua variabel adalah normal. Hasil uji normalitas data pada kelompok eksperimen tersaji pada tabel 2 .

Dari tabel 2 dapat diketahui, data tes awal kelompok eksperimen dribble 20 yards square dengan $\mathrm{L}_{\text {hitung }}=0,151<\mathrm{L}_{\text {tabel }}$ $=0,381$ yang berarti berdistribusi normal dan data tes akhir kelompok eksperimen dribble 20 yards square dengan $\mathrm{L}_{\mathrm{hitung}}=$ $0,151<\mathrm{L}_{\text {tabel }}=0,381$ yang berarti berdistribusi normal.

Uji Homogenitas dilakukan untuk melihat apakah kelompok eksperimen memiliki varians yang sama. Untuk mengetahui variabel mana saja yang memiliki varians yang sama maka uji yang dilakukan adalah dengan cara membandingkan varians terbesar dan varians terkecil dari data pretest dan posttest sehingga diperoleh nilai $F_{\text {hitung }}$ dengan kriteria uji jika nilai $F_{\text {hitung }}<\mathrm{F}_{\text {tabel }}$ maka kedua data bersifat homogen atau berasal dari varians yang sama. Ternyata pada hasil tes didapat $F_{\text {hitung }}<\mathrm{F}_{\text {tabel }}$ maka kedua varians tersebut 
homogen. Hasil uji homogenitas data pada kelompok eksperimen tersaji pada tabel 3.

Dari tabel 3, dapat diketahui hasil uji homogenitas Kelompok eksperimen dribble 20 yards square yaitu didapatkan $F_{\text {hitung }}=1,37<\mathrm{F}_{\text {tabel }}=3,33$ yang berarti data tersebut homogen.

\section{HASIL DAN PEMBAHASAN}

\section{Deskripsi Data}

1. Karakter Sampel

Data merupakan gambaran jenis data yang diperlukan untuk menganalisa data. Jenis data yang terdiri atas jumlah, rata-rata, standar deviasi, dan varians pada kelompok eksperimen yaitu latihan dribble 20 yards square. Jenis data tersebut digunakan untuk menganalisa adalah uji normalitas, uji homogenitas, dan uji hipotesis. Sehingga dapat disimpulkan bagaimana hasil perbandingan antara sebelum diberi perlakuan dan sesudah diberi perlakuan, apakah perlakuan yang diberikan dapat memberikan pengaruh untuk meningkatkan kemampuan menggiring bola. Sampel yang digunakan adalah populasi anak yang mengikuti ekstrakurikuler SMA Negeri 1 Pagar Dewa, karena jumlah populasi kurang dari 100, kemudian sampel yang digunakan adalah siswa yang berjumlah 30 orang.

Berikut ini karakteristik sampel siswa yang mengikuti ekstrakurikuler SMA Negeri 1 Pagar dewa:

a. Jenis Kelamin: Pada penelitian ini seluruh sampel berjenis kelamin laki-laki;

b. Berat Badan: Berat badan siswa yang mengikuti ekstrakurikuler rata-rata $50 \mathrm{~kg}$, pada usia 16-17 tahun;

c. Tinggi Badan: Sampel pada penelitian ini memiliki tinggi badan rata-rata $160 \mathrm{~cm}$;

d. Kegiatan Olahraga: Berdasarkan observasi, sample pada penelitian ini hanya melakukan olahraga pada saat ekstrakurikuler di sekolah pa- 
da hari jumat pukul 15.00 WIB, dikarenakan mereka dari pukul 07.00-14.00 WIB melaksanakan kegiatan belajar mengajar, dan di luar waktu itu mereka banyak yang membantu orang tua bertani.

e. Hasil Tes: Berdasarkan hasil penelitian, maka dapat digambarkan deskripsi data seperti pada tabel 4.

Tabel 4. Deskripsi Data Hasil Penelitian Kelompok Eksperimen

\begin{tabular}{|l|c|c|}
\hline \multirow{2}{*}{ Keterangan } & \multicolumn{2}{c|}{$\begin{array}{c}\text { Kelompok } \\
\text { Eksperimen }\end{array}$} \\
\cline { 2 - 3 } & $\begin{array}{c}\text { Tes } \\
\text { Awal }\end{array}$ & $\begin{array}{c}\text { Tes } \\
\text { Akhir }\end{array}$ \\
\hline Jumlah & 197 & 228 \\
\hline Rata-rata & 6,57 & 7,60 \\
\hline Standar Deviasi & 0,86 & 1,00 \\
\hline Varians & 0,74 & 1,01 \\
\hline
\end{tabular}

Berdasarkan data dari tabel 4 , diperoleh kemampuan menggiring bola kelompok eksperimen latihan dribble 20 yards square dengan nilai rata-rata tes awal 6,57 dan mengalami peningkatan pada tes akhir dengan nilai rata-rata 7,6; yang digambarkan dengan diagram batang (gambar 3).

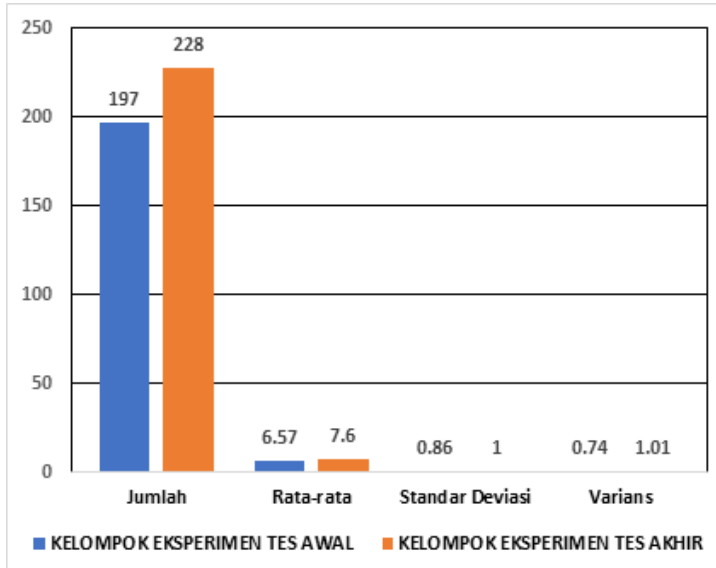

Gambar 3. Diagram Perbedaan Hasil Pretest dan Posttest

Berdasarkan diagram, didapatkan data, pada tes awal diperoleh jumlah 197, rata-rata 6,57 , standar deviasi 0,86 dan varians 0,74 , kemudian pada tes akhir mengalami peningkatan yang signifikan yaitu jumlah 228, rata-rata 7,6, standar deviasi 1, dan varians 1,01 .

Tabel 5. Hasil Perhitungan Uji Pengaruh Data Post Test

\begin{tabular}{|l|r|}
\hline \multicolumn{1}{|c|}{ Keterangan } & $\begin{array}{c}\text { Kelompok } \\
\text { Eksperimen }\end{array}$ \\
\hline Jumlah & 31 \\
\hline Rata-rata & 1,03 \\
\hline Standar Deviasi & 0,67 \\
\hline Varians & 0,45 \\
\hline Thitung & 8,48 \\
\hline Ttabel & 2,045 \\
\hline Kesimpulan & Ada pengaruh \\
\hline
\end{tabular}




\section{Pengujian Hipotesis}

Berdasarkan hasil uji normalitas dan uji homogenitas pada kelompok sampel baik tes awal maupun tes akhir maka dilakukan uji pengaruh untuk mengetahui pengaruh perlakuan pada kelompok sampel terhadap kemampuan menggiring bola, dapat dilihat pada tabel 5 .

Berdasarkan hasil perhitungan diperoleh nilai $\mathrm{t}_{\text {hitung }}=8,48>\mathrm{t}_{\text {tabel }}=2,045$ untuk $\alpha 5 \%$ dengan $\mathrm{dk}=29$, yang berarti ada pengaruh data hasil pretest dan hasil posttest kelompok eksperimen. Dengan Demikian dapat disimpulkan ada pengaruh yang signifikan dari latihan dribble 20 yards square terhadap kemampuan menggiring bola pada siswa ekstrakurikuler sepak bola SMA Negeri 1 Pagar Dewa Kabupaten Tulang Bawang Barat.

\section{Pembahasan}

Hasil penelitian yang dilakukan peneliti membahas tentang pengaruh latihan dribble 20 yards square terhadap kemampuan menggiring bola pada siswa ekstrakurikuler SMA Negeri 1 Pagar Dewa dengan jumlah sampel sebanyak 30 . Penelitian tersebut diperoleh hasil yang menunjukan bahwa terdapat pengaruh yang signifikan dari latihan dribble 20 yards square terhadap kemampuan menggiring bola pada siswa ekstrakurikuler SMA Negeri 1 Pagar Dewa. Saat menggiring, dibutuhkan kecepatan dan kelincahan serta konsentrasi yang baik untuk menggiring bola agar hasilnya dapat maksimal.

Menggiring bola merupakan teknik dasar dengan bola yang sering digunakan dalam permainan sepak bola. Harsono (1988: 204), menjelaskan bahwa: "Komponen fisik yang diperlukan dalam cabang olahraga sepak bola antara lain; kekuatan otot, daya tahan otot, fleksibilitas, kelincahan, koordinasi dan power." Menurut Sucipto, (2000: 28), “pada dasarnya menggiring bola adalah menendang terputusputus atau pelan-pelan, oleh karena itu bagian kaki yang dipergunakan dalam menggiring bola sama dengan bagian kaki yang dipergunakan untuk menendang bola." Semua bentuk menggiring bola 
yang efektif didasarkan pada kombinasi keempat kemampuan adalah: (1) kemampuan mengontrol bola/penguasaan bola, (2) kemampuan melakukan gerak tipu, (3) kemampuan mengubah arah, dan (4) kemampuan mengubah kecepatan.

Berdasarkan pengujian hipotesis ternyata ada pengaruh yang signifikan antara latihan dribble 20 yards square terhadap kemampuan menggiring bola, pada penelitian ini menunjukan bahwa latihan dribble 20 yards square memberikan pengaruh terhadap kemampuan menggiring bola dalam sepak bola. Latihan dribble 20 yards square merupakan suatu bentuk latihan yang digunakan untuk meningkatkan kecepatan dan kelincahan saat menggiring. Latihan ini sangat baik dilakukan untuk menunjang pelaksanaan teknik dasar suatu cabang olahraga khususnya pada cabang sepak bola yang salah satu faktor pentingnya adalah kemampuan menggiring bola.

Latihan dribble 20 yards square sangat efektif meningkatkan kemampuan menggiring, dikarenakan latihan dribble 20 yards square harus lebih fokus pada bola yang berada di kaki agar saat melakukannya bola tidak lepas dari penguasaan pemain, dikarenakan untuk dapat menghasilkan kecepatan menggiring yang cepat. Selain itu juga dipengaruhi faktor antara lain penguasaaan teknik dasar menggiring bola, sikap badan saat menggiring, dan perkenaan kaki dengan bola.

\section{KESIMPULAN}

Berdasarkan analisis hasil penelitian dan pembahasan, dapat disimpulkan bahwa ada pengaruh yang signifikan latihan dribble 20 yards square terhadap kemampuan menggiring bola pada siswa ekstrakurikuler sepak bola SMA Negeri 1 Pagar Dewa Kabupaten Tulang Bawang Barat.

\section{Saran}

1. Hasil penelitian ini diharapkan dapat dijadikan referensi sebagai alternatif untuk meningkatkan kemampuan menggiring sepak bola khususnya pada 
para siswa SMA Negeri 1 Pagar Dewa

Kabupaten Tulang Bawang Barat.

2. Hasil penelitian ini diharapkan dapat memberikan kontribusi untuk mengembangkan ilmu pengetahuan olahraga (IPTEKOR) khususnya dalam meningkatkan kemampuan menggiring sepak bola.

3. Agar hasil penelitian lebih komperhensif maka sebaiknya jumlah sampel ditambah dan bentuk latihan ditambah pula.

\section{DAFTAR PUSTAKA}

Arikunto, Suharsimi, (1998). Prosedur penelitian suatu pendekatan praktek. Jakarta: PT Rineka Cipta.

Abid, Wan Muhlish El, dkk. (2013). Pengaruh latihan sasaran menggunakan ban bekas terhadap hasil shooting permainan sepak bola Siswa Hidayatul Muhsinin. UNTAN. Vol 2.

Bompa, Tudor O. (1983). Theory and methodology of training. Dubud: Kendall/Hunt Compani.

Febrianto, Ferry dan Arif Bulqini. (2017). Analisis teknik dasar permainan sepak bola klub Sinar Harapan Tulangan Sidoarjo Pada Liga 3 Regional Jatim. UNESA. Vol.2 No.1.
Gardasevic, J., \& Bjelica, D. (2008). The effect of the training in the preparation period on the dribbling speed with fifteen years old football players: strength and conditioning journal, vol. 20.

Gusnanda, M. (2013). Pengaruh latihan mengiring bola cone ke cone terhadap kelincahan mengiring bola (dribbling) pada permainan bola kaki siswa ekstrakurikuler SMA 2 Kampar: Universitas Riau.

Harsono. (1988). Coaching dan aspekaspek psikologis dalam olahraga. Jakarta: CV. Tambak Kusuma.

Koger, Robert. (2007). Latihan dasar andal sepak bola remaja. Klaten: Macanan Jaya Cemerlang.

Lutan, Rusli. (1988). Belajar keterampilan motorik, pengamat teori dan metode. Jakarta: Depdikbud Dirjen dikti PPLPTK.

Luxbacher, Joseph A. (1997). Sepak bola taktik \& teknik bermain. Jakarta: PT Raja Grafindo Persada.

Nenggala, Asep Kurnia. (2006). Pendidikan jasmani, kesehatan, dan olahraga kelas vii. Jakarta: Grafindo Media Pratama.

Paturisi, Ahmad. (2012). Managemen pendidikan jasmani dan olahraga. Jakarta: Rineka Cipta.

Plainos, C., et al. (2011). Comparison of two different training methods for improving dribbling and kicking skills of young football players. The sport journal, vol. 14.

Sugiyono. (2015). Metode pendidikan pendekatan penelitian kuantitatif kualitatif dan $r \& d$. Bandung. Alfabeta. 15 No. 5. 